\title{
含单一萠基冠状共轭分子的合成、表征和光物理性质
}

\author{
李璟桃 $a$ 庄桂林 $b$ 黄 强 $a$ 王进义 $a$ 吴亚宇 $a$ 杜平武 $* a$ \\ ( ${ }^{a}$ 中国科学技术大学化学与材料科学学院 合肥 230026) \\ ( $b$ 浙江工业大学化学工程学院 杭州 310032)
}

\begin{abstract}
摘要 由于独特的结构和物理性质, 大环共轭化合物引起了研究者广泛关注. 报道了含单个萠单元的[7]环对苯基-2,7萠([7]CPPPy 2,7)大环分子的合成方法和光物理性质. 通过含弯曲结构的前驱体和萠的双硼酸酯化底物的 Suzuki-Miyanra 偶联反应，加入亚锡酸还原芳构化，该分子的成功制备被质谱及系列相关核磁共振谱图等表征证实. 新化合物的光物 理性质通过紫外-可见光谱等测试方法进一步研究, 其最大紫外吸收峰出现在 $326 \mathrm{~nm}$, 与理论计算结果相吻合. 在 350 $\mathrm{nm}$ 波长光激发下, 其荧光激发峰值出现在 $492 \mathrm{~nm}$ 处. 计算结果表明, 该化合物的应变能为 $299.17 \mathrm{~kJ}^{\circ} \mathrm{mol}^{-1}$.
\end{abstract}

关键词 共轭大环分子; 分子环; 多环芳烃; 萠

\section{A Conjugated Molecular Crown Containing a Single Pyrenyl Unit: Synthesis, Characterization, and Photophysical Properties}

\author{
Li, Jingshi ${ }^{a}$ \\ Zhuang, Guilin ${ }^{b}$ \\ Huang, Qiang ${ }^{a}$ \\ Wang, Jinyi ${ }^{a}$ \\ $\mathrm{Wu}, \mathrm{Yayu}^{a}$ \\ Du, Pingwu ${ }^{*, a}$ \\ ( ${ }^{a}$ Department of Materials Science and Engineering, University of Science and Technology of China, Hefei 230026) \\ ( ${ }^{b}$ College of Chemical Engineering, Zhejiang University of Technology, Hangzhou 310032)
}

\begin{abstract}
Macrocyclic $\pi$-conjugated materials have attracted much attention due to their unique structures and physical properties. The synthetic methods and physical properties of a $\pi$-extended molecular crown containing a single pyrenyl unit, cyclo[7]paraphenylene-2,7-pyrenylene ([7]CPPPy2,7), were report. This macrocycle was achieved by a rationally designed Suzuki-Miyanra coupling of a curved precursor and pyrene-2,7-bis(boronate), followed by reductive aromatization with stannous acid, and confirmed by various physical characterizations, such as HR-MS and a series of NMR spectroscopies. The photophysical properties of [7]CPPPy 2,7 were further studied by UV-vis spectroscopy and other analysis, and its maximum absorption peak was located at $326 \mathrm{~nm}$, which was consistant with density functional theory (DFT) calculations. The fluorescence emission spectrum of [7]CPPPy 2,7 was further studied. Under $350 \mathrm{~nm}$ excitation, the emission peak appeared at $492 \mathrm{~nm}$. The computational result indicates the strain energy of [7]CPPPy 2,7 is as high as $299.17 \mathrm{~kJ}^{\circ} \mathrm{mol}^{-1}$.

Keywords $\pi$-conjugated macrocycle; molecular crown; polyaromatic hydrocarbon; pyrene
\end{abstract}

\section{Introduction}

Fully $\pi$-conjugated macrocycles and their derived hoop-shaped molecules have attracted increasing attention due to their unique structures and physical properties. ${ }^{[1]}$ Various conjugated macrocycles have been reported in the literature and considerable efforts have been devoted into developing new synthesis strategies. ${ }^{[2]}$ In addition, conjugated macrocycles have shown great potential applications in many fields, such as chemical sensors, ${ }^{[3]}$ molecular devices, ${ }^{[4]}$ nonlinear optical materials ${ }^{[5]}$ and ion channels. ${ }^{[6]}$ Since 2008, the hoop-shaped cycloparaphenylenes (CPPs, Scheme 1a) were reported by different synthetic methods, in which 1,4-connected phenyl rings form conjugated macrocycles, representing the smallest segments of armchair carbon nanotubes $(\mathrm{CNTs}){ }^{[7]}$ Our group synthesized a series of $\pi$-extended hoop-shaped carbon nanotube segments and found that significant redshifts in both absorption and emi-

\footnotetext{
* Corresponding author. E-mail: dupingwu@ustc.edu.cn

Received December 5, 2020; revised February 8, 2021; published online February 26, 2021.

Project supported by the National Key Research and Development Program of China (No. 2017YFA0402800), the National Natural Science Foundation of China (Nos. 21971229, 51925206, U1932214) and the Zhejiang Provincial Natural Science Foundation (No. LR19B010001).

国家重点研发计划(No. 2017YFA0402800)、国家自然科学基金(Nos. 21971229, 51925206, U1932214)、浙江省自然科学基金(No. LR19B010001)资助项 目.
} 
ssion spectra were observed compared with CPP analogues. ${ }^{[8]}$ Cong and coworkers ${ }^{[9]}$ reported a few anthracenebased carbon nanohoops and some showed interesting chiral properties. Tan and coworkers ${ }^{[10]}$ recently reported that the carbon nanohoop can host a fullerene-trithiasumanene supramolecular complex. Jiang and coworkers ${ }^{[11]}$ designed four different cycloparaphenylene-based macrocyclic molecules and demonstrated that these nonplanar $\pi$-conjugated CPP nanocycles can self-assemble into multilamellar, crystalline vesicles in tetrahydrofuran/water mixed solvent. Besides, other $\pi$-conjugated macrocycles are also attracting much attention. Through iterative Diels-Alder reactions utilizing a "C"-shaped building block, Miao and coworkers $^{[12]}$ synthesized an undocumented zigzag carbon nanobelt. Taking advantages of resorcin[4]arenes, Wang and coworkers $^{[13]}$ explored the synthesis of belt-shaped molecules simply by converting the hydroxy groups into alkylating moieties and then stitching the fjords via intramolecular alkylation reactions. $\mathrm{Wu}$ and coworkers ${ }^{[14]}$ recently report a facile synthetic strategy to obtain aryl-substituted soluble cycloarenes with different sizes, involving macro- (a)

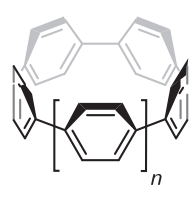

$[n+4] \mathrm{CPP}$ (b)

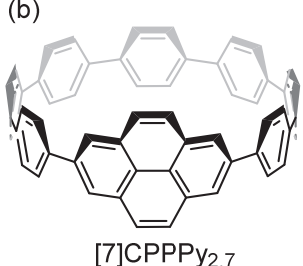

Scheme 1 Molecular structures of (a) $[n+4]$ cycloparaphenylene $([n+4] \mathrm{CPP})$, and (b) a molecular crown containing a single pyrenyl unit, [7]CPPPy 2,7 cyclization by the Suzuki coupling reaction, followed by bismuth(III) triflate-catalyzed cyclization of vinyl ethers.

The introduction of pyrenyl moiety in a conjugated macrocycle can provide a large $\pi$-conjugated system and additional reactive sites. ${ }^{[15]}$ However, the cyclic crownshaped structure containing a single pyrenyl unit has not been synthesized yet. In the present work, we report a facile synthesis approach to make cyclo[7]paraphenylene-2,7pyrenylene ([7]CPPPy 2,7 , the number 2, 7 indicate bonding sites of the pyrenyl unit and framework region, Scheme 1b) as a $\pi$-extended [9,9] carbon nanotube segment. [7]СРPРy ${ }_{2,7}$ is achieved by a rationally designed Suzuki-Miyanra coupling of a curved precursor and pyrene-2,7-bis(boronate), followed by reductive aromatization. The product was confirmed by high-resolution mass spectrometry (MALDITOF-MS) and nuclear magnetic resonance (NMR) spectroscopies. Its photophysical properties were investigated by steady-state spectroscopy and theoretical calculations.

\section{Results and discussion}

To insert one pyrene moiety into a carbon macrocycle, a synthesis strategy by reacting the pyrene with a curved precursor was designed (Scheme 2). Compound $\mathbf{5}$ is a good candidate to react with pyrene, which contains three substituted cyclohexadienyl rings to alleviate strain energy during the macrocyclization step. In addition, these cyclohexadienyl structures have specific angles, which is helpful in the formation of conjugated macrocyclic systems.

Initially, compounds $\mathbf{1}$ and $\mathbf{3}$ were synthesized according to the reported method. ${ }^{[16]}$ Although compound 1 could be used as the starting material for the synthesis of compound $\mathbf{4}$, an alternative route from $\mathbf{3}$ has a much higher yield be-

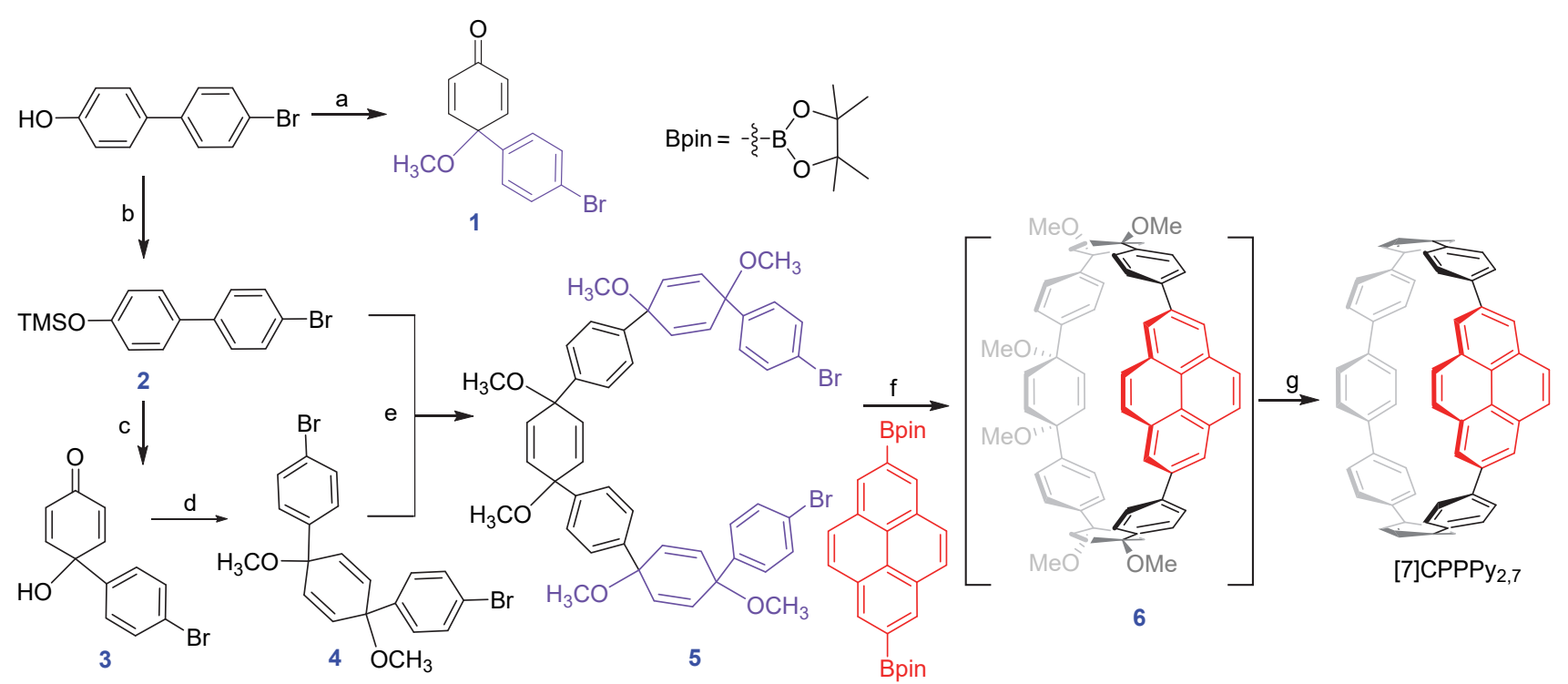

Reaction conditions: (a) (diacetoxyiodo)benzene, $\mathrm{MeOH}$, r.t., $72 \mathrm{~h}, 80 \%$; (b) imidazole, trimethyl chlorosilane, $\mathrm{CH}_{2} \mathrm{Cl}_{2}, 0{ }^{\circ} \mathrm{C}, 16 \mathrm{~h}, 95 \%$; (c) (diacetoxyiodo)benzene, THF/MeCN/H $\mathrm{H}_{2} \mathrm{O}$, r.t., $16 \mathrm{~h}, 68 \%$; (d) (1) $\mathrm{NaH}$, THF, $0{ }^{\circ} \mathrm{C}, 3 \mathrm{~h}$; (2) 1,4-dibromobenzene, $n$-BuLi, THF, $-78{ }^{\circ} \mathrm{C}, 2 \mathrm{~h}$; (3) $\mathrm{NaH}, \mathrm{Mel}, \mathrm{THF}, 0{ }^{\circ} \mathrm{C}, 8 \mathrm{~h}, 62 \%$ (three steps from compound 3); (e) (1) $n$-BuLi, THF, $-78{ }^{\circ} \mathrm{C}, 2 \mathrm{~h}$; (2) NaH, Mel, THF, $0{ }^{\circ} \mathrm{C}, 8 \mathrm{~h}, 57 \%$ (two steps from compound 4); (f) $\mathrm{Pd}\left(\mathrm{PPh}_{3}\right)_{4}, \mathrm{KOH}, \mathrm{THF} / \mathrm{H}_{2} \mathrm{O}, 80{ }^{\circ} \mathrm{C}, 48 \mathrm{~h}$; (g) $\mathrm{H}_{2} \mathrm{SnCl}_{4}$, THF, r.t., $4 \mathrm{~h}, 21 \%$ (two steps from compound 5)

Scheme 2 Synthetic route for [7]CPPPy2,7 
cause the hydroxyl group can significantly enhance the stereo-selectivity for syn isomer due to the electrostatic interaction. ${ }^{[17]}$ After deprotonation of compound 3 with sodium hydride in tetrahydrofuran (THF), (4-bromophenyl)lithium was added to the mixture. The resulting crude product was then alkylated with methyl iodide to produce compound 4 in a yield of $62 \%$. Then, the subsequent reaction between compounds $\mathbf{4}$ and $\mathbf{1}$ can generate the key curved compound $\mathbf{5}$ in a yield of $57 \%{ }^{[18]}$

Next, 2,7-bis(4,4,5,5-tetramethyl-1,3,2-dioxaborolan-2yl)pyrene was prepared under iridium-catalyzed borylation conditions, ${ }^{[19]}$ which was then reacted with 5 by a Suzuki coupling reaction $\left(80{ }^{\circ} \mathrm{C}\right.$ for $48 \mathrm{~h}, \mathrm{Pd}\left(\mathrm{PPh}_{3}\right)_{4}$ as the catalyst, and $\mathrm{KOH}$ as the base) to afford the macrocycle intermediate 6 . The following reductive aromatization by $\mathrm{H}_{2} \mathrm{Sn}-$
$\mathrm{Cl}_{4}$ in THF was conducted, producing the target compound [7]CPPPy 2,7 as green-yellow solid in a yield of $20.5 \%$ over two steps.

The successful synthesis of [7]CPPPy 2,7 was confirmed by ${ }^{1} \mathrm{H}$ NMR, ${ }^{13} \mathrm{C}$ NMR spectroscopies and MALDI-TOF mass spectrometry (Figure 1). The isotopic patterns observed at $\mathrm{m} / z$ 732.2870 in the high-resolution MALDI-TOF mass spectrometry (Figures 1a and S1) matched well with their simulated values (calculated for $\mathrm{C}_{58} \mathrm{H}_{36}[\mathrm{M}]^{+}$: 732.2817). The ${ }^{1} \mathrm{H}$ NMR spectrum of [7]CPPPy 2,7 in $\mathrm{CDCl}_{3}$ is shown in Figures $1 \mathrm{~b}$ and S2. Apparently, all protons, including two singlets at $\delta 8.17$ and 7.88, a set of doublets at $\delta 7.67$ and the multiplets at $\delta 7.52 \sim 7.43$, appear in the region of $\delta 7.43 \sim 8.17$. These chemical shifts can be attributed to all the aromatic protons in [7]CPPPy 2,7 , which (a)

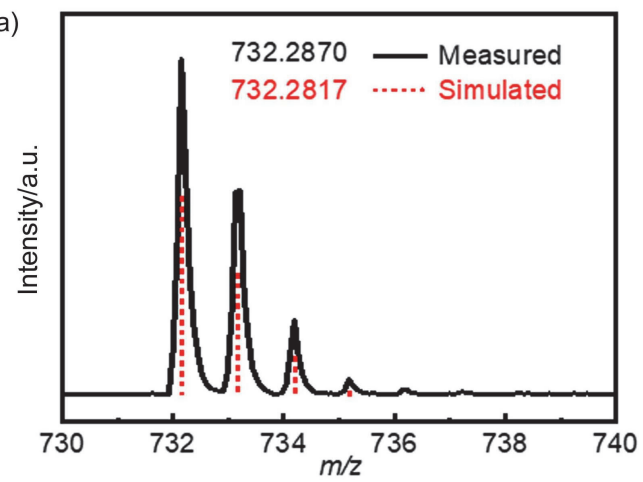

(c)

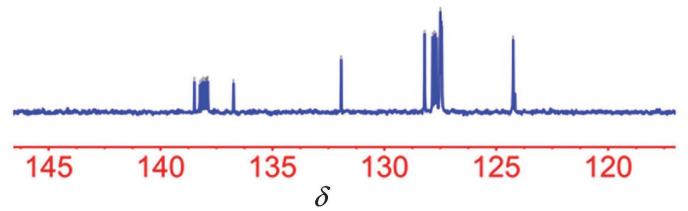

(e)

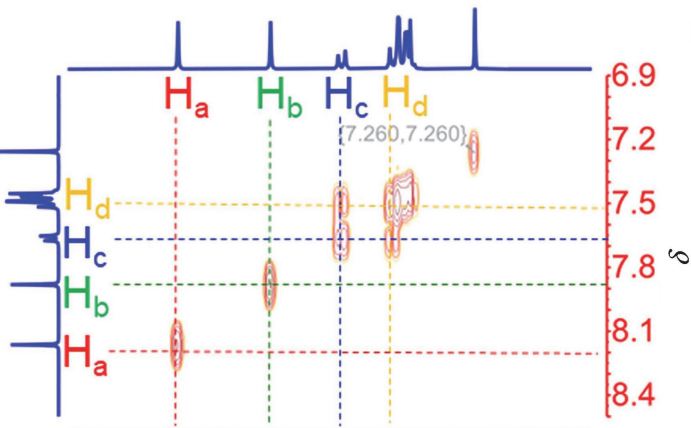

$\begin{array}{llllllllllll}8.5 & 8.3 & 8.1 & 7.9 & 7.7 & 7.5 & 7.3 & 7.1 & 6.9\end{array}$

$\delta$ (b)

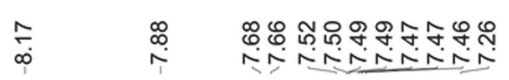

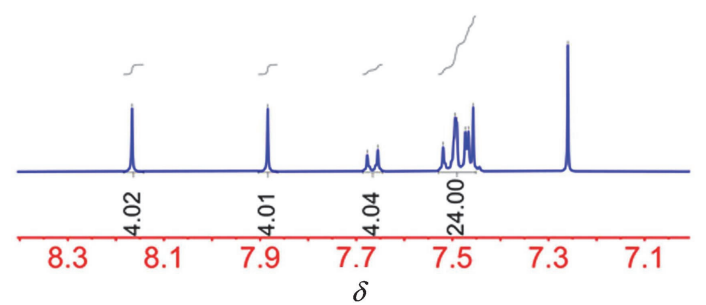

(d)

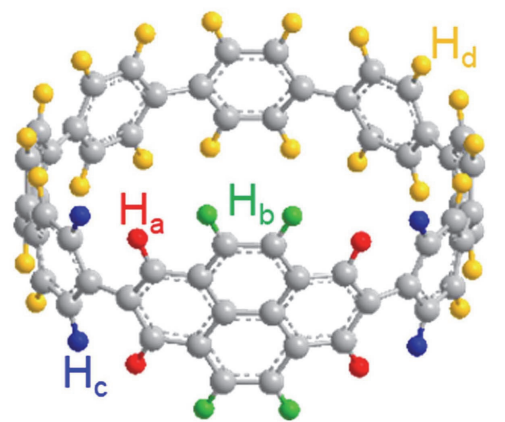

(f)

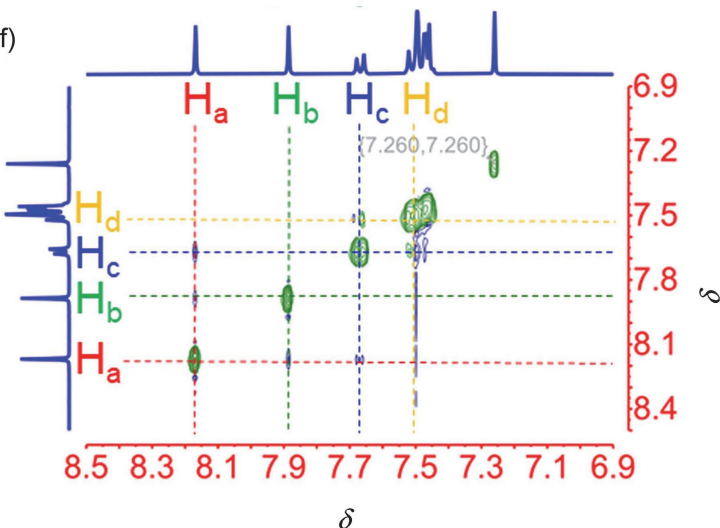

Figure 1 Characterization spectra for [7]CPPPy2,7

(a) Partial HR-MS (MALDI-TOF) data. (b) Partial ${ }^{1} \mathrm{H}$ NMR spectra of [7]CPPPy ${ }_{2,7}$ in $\mathrm{CDCl}_{3}$. (c) Partial ${ }^{13} \mathrm{C}_{\mathrm{NMR}}$ spectra of $[7] \mathrm{CPPPy}_{2,7}$ in $\mathrm{CDCl}_{3}$. (d) Classification of protons in [7]CPPPy $\mathrm{y}_{2,7}$. (e) Expanded $2 \mathrm{D}^{1} \mathrm{H}^{-1} \mathrm{H}$ COSY NMR spectra $\left(400 \mathrm{MHz}, \mathrm{CDCl}_{3}\right.$ ) of [7]CPPPy $\mathrm{C}_{2,7}$. (f) Expanded 2D ${ }^{1} \mathrm{H}-{ }^{1} \mathrm{H}$ NOESY NMR spectra $\left(400 \mathrm{MHz}, \mathrm{CDCl}_{3}\right.$ ) of [7] $\mathrm{CPPPy}_{2,7}$ 
are consistent with the carbon signals ranging from $\delta 124.24$ to $\delta 138.49$ in ${ }^{13} \mathrm{C}$ NMR spectrum (Figure 1c and Figure $\mathrm{S} 3)$. To fully assign the aromatic proton signals in [7]CPPPy 2,7 (Figure 1d), 2D ${ }^{1} \mathrm{H}_{-}{ }^{1} \mathrm{H}$ COSY NMR and NOESY NMR measurement were further carried out (Figures 1e and 1f). Based on these results, the characteristic peaks at $\delta 8.16$ and 7.88 can be assigned to protons in the pyrenyl unit because of their singlet peak patterns and absence of interaction with other peaks. Especially, considering the correlation with the singlet at $\delta 8.16$ in NOESY NMR spectrum (Figure 1f), the peak at $\delta 7.88$ should be ascribed to protons at the 4-, 5-, 9-, and 10-positions $\left(\mathrm{H}_{\mathrm{b}}\right)$. Then, the singlet at $\delta 8.16$ can be assigned to protons at the 1-, 3-, 6-, and 8-positions $\left(\mathrm{H}_{\mathrm{a}}\right)$. And these two peaks is consistent with the previously reports. ${ }^{[20]}$ Notably, the doublets at $\delta 7.66$ is interacted with $\mathrm{H}_{\mathrm{a}}$ and correlated with the multiple signals at $\delta 7.44 \sim 7.52$ in both $2 \mathrm{D}{ }^{1} \mathrm{H}-{ }^{1} \mathrm{H}$ COSY and NOESY NMR spectra, which can be assigned to four protons in the phenyl groups next to the pyrenyl unit $\left(\mathrm{H}_{\mathrm{c}}\right)$. The multiplets at $\delta$ $7.52 \sim 7.43$ could be ascribed to all the other protons on the cyclic phenyl frameworks $\left(\mathrm{H}_{\mathrm{d}}\right) . \mathrm{H}_{\mathrm{d}}$ showed obvious interaction with $\mathrm{H}_{\mathrm{c}}$ in the COSY NMR spectrum. All these characterizations verified the successful synthesis of this new conjugated macrocycle.

The photophysical properties of [7]CPPPy, 2 were studied by UV-vis absorption and fluorescence spectroscopies at room temperature (Figure 2a, black plot). For comparison, [9]CPP (red plot) and pyrene monomer (blue plot) were used as reference compounds. The absorption bands of [7]СРPPy 2,7 were observed between 300 and $420 \mathrm{~nm}$ and the maximum absorption peak $\left(\lambda_{\max }\right)$ was located at $\lambda=326$ $\mathrm{nm}$ with the absorption coefficient of $\varepsilon=9.6 \times 10^{4} \mathrm{~L} \cdot \mathrm{mol}^{-1}$ • $\mathrm{cm}^{-1}$. An absorption shoulder peak was also observed at $\lambda=340 \mathrm{~nm}$. It is worth mentioning that the maximum of the absorption bands have a little blueshift $(14 \mathrm{~nm})$ in comparison with the reference compound [9]CPP $\left(\lambda_{\max }=340 \mathrm{~nm}\right.$, $\left.\varepsilon=4.8 \times 10^{4} \mathrm{~L} \cdot \mathrm{mol}^{-1} \cdot \mathrm{cm}^{-1}\right)$. Apparently, both [7]CPPPy 2,7 and [9]CPP had similar absorption characteristics in the range of $300 \sim 370 \mathrm{~nm}$. Interestingly, the shoulder peak of [7]CPPPy 2,7 and the maximum absorption peak of [9]CPP centered at nearly the same absorption wavelength. This phenomenon could be ascribed to the same molecular size and relevant frontier energy levels. [7]CPPPy 2,7 has significant difference from pyrene which has the absorption bands between 250 and $350 \mathrm{~nm}$ maximized at $\lambda_{\max }=337$ $\mathrm{nm}, 307 \mathrm{~nm}$, and $322 \mathrm{~nm}$. The molecular absorption coefficient for the $\lambda_{\max }$ of [7]CPPPy 2,7 is about two times higher than that of [9]CPP. Given the fact that the $\varepsilon$ of pyrene $\left(\lambda_{\max }=337 \mathrm{~nm}, \varepsilon=5.0 \times 10^{5} \mathrm{~L} \cdot \mathrm{mol}^{-1} \cdot \mathrm{cm}^{-1}\right)$ is much larger than that of [9]CPP $\left(\lambda_{\max }=340 \mathrm{~nm}, \varepsilon=4.8 \times 10^{4} \mathrm{~L} \cdot \mathrm{mol}^{-1} \bullet\right.$ $\mathrm{cm}^{-1}$ ), the pyrenyl moiety can change the electronic structure of [9]CPP and influence its energy levels. The fluorescence emission spectra of [7]CPPPy $2,7,[9] \mathrm{CPP}$ and pyrene were further studied at room temperature excited at 350 $\mathrm{nm}$. In sharp contrast to pyrene, [7]CPPPy $\mathrm{C}_{2,7}$ has no characteristics of pyrene and only shows a broad band in the range of $290 \sim 370 \mathrm{~nm}$ (maximized at $492 \mathrm{~nm}$, black plot), which is similar to [9]CPP (maximized at $497 \mathrm{~nm}$, red plot). These interesting results confirmed significant influence of the cyclic structures, which could explain why [7]CPPPy $\mathrm{C}_{2,7}$ and [9]CPP showed similar intense green photoluminescence (Figure 2a, inset, excited at $365 \mathrm{~nm}$ ). The fluorescence quantum yield of [7] $\mathrm{CPPPy}_{2,7}$ is determined to be $\Phi_{\mathrm{f}}=46.7 \%$ by using anthracene in ethanol as the reference $\left(\Phi_{\mathrm{f}}=30 \%\right){ }^{[21]}$

Moreover, the luminescence lifetime $\left(\tau_{\mathrm{s}}\right)$ of [7]CPPPy $\mathrm{CP}_{2,7}$ was measured by time-resolved fluorescence decay (Figure $2 b)$. These measurements were performed using a nanosecond pulsed laser system excited at $390 \mathrm{~nm}$ in degassed $\mathrm{CH}_{2} \mathrm{Cl}_{2}$ solution. The fluorescence decay of [7]CPPPy $\mathrm{y}_{2,7}$ follows the first-order kinetics with a lifetime $\tau_{\mathrm{s}}=9.2 \mathrm{~ns}$ at $492 \mathrm{~nm}$ by linear fitting decay, which is similar to the lifetime for [9]CPP $\left(\tau_{\mathrm{s}}=9.7 \mathrm{~ns}\right)$ under the same conditions. ${ }^{[8 \mathrm{~b}]}$
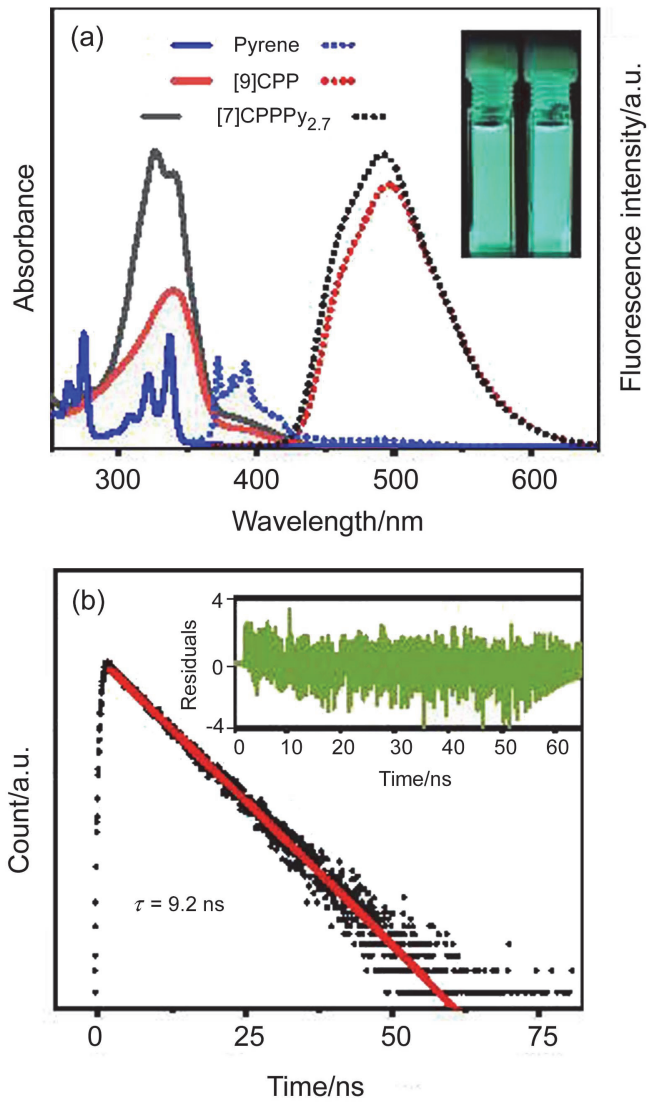

Figure 2 (a) UV-vis absorption (solid lines) and fluorescence spectra (short dot lines) of pyrene (blue), [9]CPP (red) and [7]CPPPy2,7 (black) in $\mathrm{CH}_{2} \mathrm{Cl}_{2}$ (inset: photographs of the fluorescence of [9] CPP (left) and [7] CPPPy2,7 (right) in $\mathrm{CH}_{2} \mathrm{Cl}_{2}$ under UV irradiation $(\lambda=365 \mathrm{~nm})$ ); (b) Emission lifetime measured at $\lambda=492 \mathrm{~nm}$ for [7]CPPPy 2,7 in $\mathrm{CH}_{2} \mathrm{Cl}_{2}$ (insert: curve-fitting residuals for [7]CPPPy2,7)

Based on its excellent fluorescence properties, such as long-time fluorescent lifetime, pure blue fluorescence, and high carrier mobility, pyrene has been widely used in organic materials. ${ }^{[2]}$ However, the formation of $\pi$-aggregation/excimer in concentrated solution or solid state can cause fluorescence quenching and reduce luminescence 
quantum efficiency. ${ }^{[23]}$ This phenomenon significantly affects its application as a luminescent material. As showed in Figure $3 \mathrm{a}$, when the concentration of pyrene exceeds $1.0 \times 10^{-3} \mathrm{~mol} / \mathrm{L}$, a new broad band appears maximized at $\sim 470 \mathrm{~nm}$, which is consistent with reported pyrene $\pi-\pi$ stacking. ${ }^{[24]}$ When the pyrenyl unit is introduced into CPP structure in [7]CPPPy 2,7 , the $\pi-\pi$ stacking is suppressed and no characteristic emission peak is observed (Figure $3 b$ ). The emission spectra of [7] CPPPy ${ }_{2,7}$ still keep its original shape as a single broad emission band maximized at $492 \mathrm{~nm}$, even the concentration is up to $1.0 \times 10^{-2} \mathrm{~mol} / \mathrm{L}$ in $\mathrm{CH}_{2} \mathrm{Cl}_{2}$. Compared with the fluorescence spectra of [9]CPP, [7]CPPPy 2,7 did not show the typical luminescence characteristics of pyrene group and their emission spectra were almost identical (Figure 2a). Therefore, the fluorescence emission peak at $492 \mathrm{~nm}$ should be attributed to the entire conjugated macrocycles including the pyrene unit. The experimental results showed that no excimer was observed for [7]CPPPy 2,7 under different concentrations. The concentration effect of [7]CPPPy ${ }_{2,7}$ (Figure 3b) indicated that no effective intermolecular aggregation could be formed between [7]СРPРy 2,7 molecules, which might result from the non-planar character of the molecular structure.
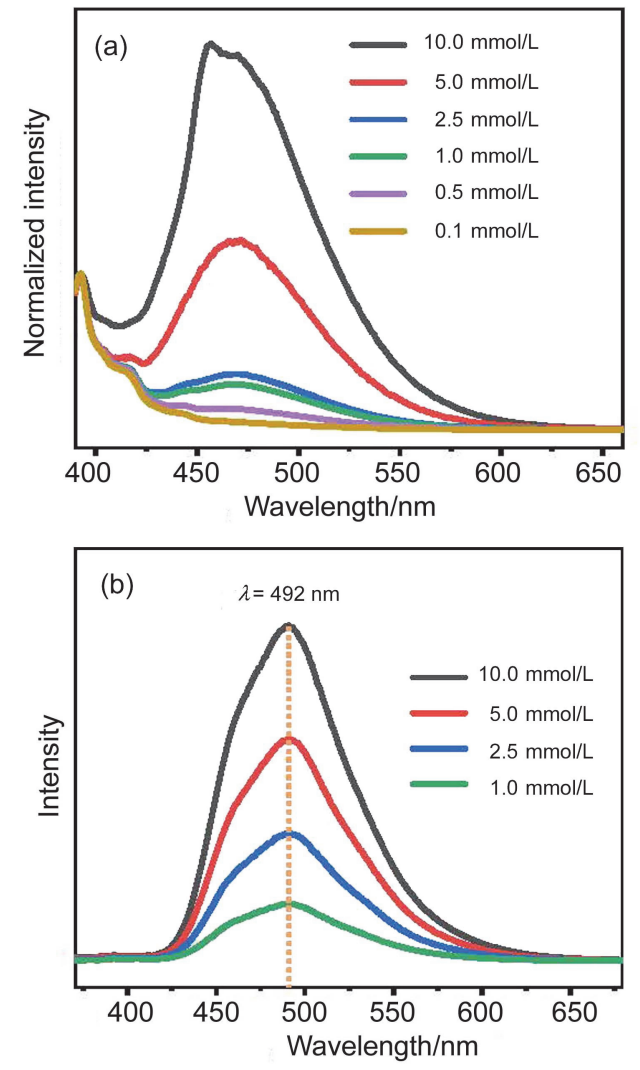

Figure 3 Concentration-dependent fluorescence spectra of (a) pyrene and (b) [7] $\mathrm{CPPPy}_{2,7}$ in $\mathrm{CH}_{2} \mathrm{Cl}_{2}$

All the fluorescence spectra were obtained by exciting samples at $\lambda=350$ $\mathrm{nm}$

In order to reveal the physical properties and the difference between [9]CPP and [7]CPPPy 2,7 , density functional theory (DFT) calculations were performed using computa- tional level of B3LYP/6-31G(d, p) in Gaussian 09. ${ }^{[25,8]}$ Geometrical optimization results indicate that twist angles between adjacent phenylene units are generated at $157.90^{\circ}$ for $[7] \mathrm{CPPPy}_{2,7}$ and $\sim 153.35^{\circ}$ for [9]CPP. The strain energy for [7]CPPPy 2,7 was estimated to be 299.17 $\mathrm{kJ} \bullet \mathrm{mol}^{-1}$, which is higher than that for [9]CPP (279.54 $\left.\mathrm{kJ} \cdot \mathrm{mol}^{-1}\right) .{ }^{[26]}$ Frontier orbital analysis reveals that both of them feature $\pi$-type bonding occupied orbitals and $\pi$-type anti-bonding unoccupied orbitals (Figure 4, Figures S1 and S2). As showed in Figure 4, both HOMO and LUMO for these two molecules exhibited similar populations on the $\pi$-type orbitals of all phenyl rings. The distinction between their HOMO-LUMO gaps (3.317 eV for [7]CPPPy $\mathrm{C}_{2,7}$ and $3.362 \mathrm{eV}$ for [9]CPP) is attributed to their configurational differences, such as twist angles and $\pi$-conjugation. Energy levels of $\mathrm{HOMO}-1$ and $\mathrm{LUMO}+1$ between them feature appreciable differences: $\mathrm{HOMO}-1$ of $-5.496 \mathrm{eV}$ and $\mathrm{LUMO}+1$ of $-1.639 \mathrm{eV}$ for [7]CPPPy ${ }_{2,7}$, as well as $\mathrm{HOMO}-1$ of $-5.617 \mathrm{eV}$ and LUMO +1 of $-1.403 \mathrm{eV}$ for [9]CPP (Figure 4, Table S1). Such phenomena probably result from different orbital populations. According to the computational results, the $\mathrm{HOMO}-1$ and $\mathrm{LUMO}+1$ orbitals of [7] $\mathrm{CPPPy}_{2,7}$ only involve the pyrenyl unit, while those of [9]CPP concentrate on seven phenyl rings. Furthermore, time-dependent DFT calculations results (Table S2) reveal that adsorption peak of $340 \mathrm{~nm}$ in [9]CPP can be mainly assigned to the transitions $(\mathrm{HOMO} \rightarrow \mathrm{LUMO}+2$ and $\mathrm{HOMO}-1 \rightarrow$ LUMO), while dual absorption peaks of [7] $\mathrm{CPPPy}_{2,7}$ can be mainly attributed to the transitions $(\mathrm{HOMO}-2 \rightarrow$ LUMO and $\mathrm{HOMO} \rightarrow$ LUMO +1$)$ for 340 $\mathrm{nm}$ and the transitions $(\mathrm{HOMO}-1 \rightarrow \mathrm{LUMO}+1)$ for 326 $\mathrm{nm}$. Therefore, the frontier orbital populations demonstrate that the existence of pyrenyl unit essentially affects the changes of absorption feature in [7]CPPPy 2,7 .

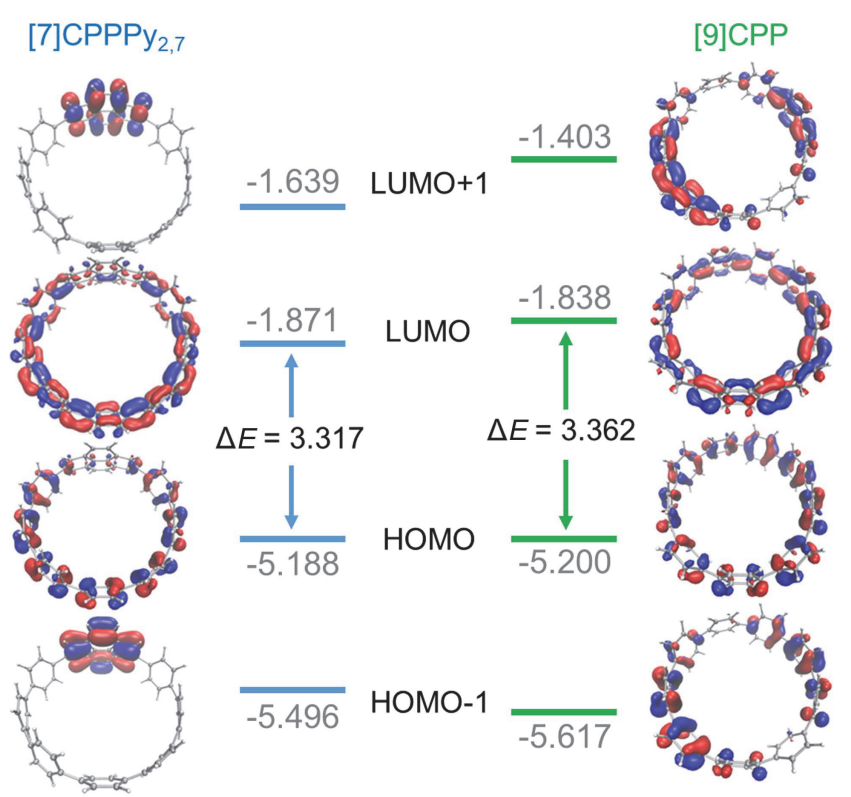

Figure 4 Comparison of some frontier molecular orbitals of [7]CPPPy 2,7 and [9]CPP 


\section{Conclusions}

In summary, we have successfully synthesized a $\pi$-extended carbon nanoring [7]CPPPy ${ }_{2,7}$ containing a single pyrenyl unit by rationally designed Suzuki-Miyanra coupling of a curved precursor and pyrene-2,7-bis(boronate). Comparison of [7]CPPPy 2,7 and [9]CPP demonstrated that the cyclic frameworks are important to their physical properties, but they could not eliminate the particularity of pyrenyl units. The photophysical properties of [7]СРPРy 2,7 showed enhanced fluorescent quantum yield. The computational result indicates that its strain energy is 299.17 $\mathrm{kJ} \bullet \mathrm{mol}^{-1}$. Further research will focus on synthesis of carbon nanorings containing other $\pi$-extended polyaromatic hydrocarbons and explore their unique physical properties.

\section{Experimental section}

\subsection{Instrumentation and materials}

NMR spectra were recorded on Bruker BioSpin $\left({ }^{1} \mathrm{H}\right.$ NMR $400 \mathrm{MHz},{ }^{13} \mathrm{C}$ NMR $100 \mathrm{MHz}$ ) spectrometer, and chemical shifts were reported as the $\delta$ scale relative to $\mathrm{CDCl}_{3}\left(\delta\right.$ 7.26) for ${ }^{1} \mathrm{H} \mathrm{NMR}$ and $\mathrm{CDCl}_{3}\left(\delta\right.$ 77.0) for ${ }^{13} \mathrm{C}$ NMR. High resolution mass spectrometry (HR-MS) analyses were carried out using MALDI-TOF-MS techniques. Flash chromatography was performed on silica gel (200 to 300 mesh). Preparative thin-layer chromatography (PTLC) experiments were performed using silica gel GF 254 coated plates. UV-vis absorption spectra were performed on a UNIC-3802 spectrophotometer. The steady state photoluminescence (PL) spectra were obtained using a HORIBA FluoroMax-4, spectrofluorimeter with an excitation source of 150-watt ozone-free continuous-wave Xenon lamp. Emission lifetime measurements were carried out using HORIBA FluoroCube-JY system with a NanoLED-390 pulsed diode light sourse. All solvents for syntheses were dried by distillation under nitrogen prior to use (tetrahydrofuran was distilled after reflux with sodium under nitrogen). Other chemicals were obtained from commercial suppliers (Aldrich or Acros) and used without further purification. All of air-sensitive reactions were carried out under nitrogen or argon atmosphere.

\subsection{General procedures}

To obtain [7]CPPPy 2,7 , compounds $\mathbf{1}, \mathbf{2}, \mathbf{3}, \mathbf{4}, \mathbf{5}$ and 2,7-bis(4,4,5,5-tetramethyl-1,3,2-dioxaborolan-2-yl)pyrene were prepared according to reported procedures. ${ }^{[19 a, 8 a]}$

\subsection{Synthesis of [7]CPPPy 2,7}

To a degassed solution of 5 (163 $\mathrm{mg}, 0.19 \mathrm{mmol})$ and 2,7-bis(4,4,5,5-tetramethyl-1,3,2-dioxaborolan-2-yl)pyrene (91 mg, $0.20 \mathrm{mmol})$ in THF $(250 \mathrm{~mL})$ and $\mathrm{H}_{2} \mathrm{O}(8 \mathrm{~mL})$, potassium hydroxide $(138 \mathrm{mg}, 12.45 \mathrm{mmol})$ and $\mathrm{Pd}\left(\mathrm{PPh}_{3}\right)_{4}$ (46 mg, $40 \mu \mathrm{mol}$ ) were added as base and catalyst respectively. The mixture was sparged with argon for another 15 min, and heated at $80{ }^{\circ} \mathrm{C}$ for $48 \mathrm{~h}$. After cooling to room temperature, the reaction mixture was concentrated by removing THF under reduced pressure. Then the crude residue was washed with brine, and water layer obtained was extracted with $\mathrm{CH}_{2} \mathrm{Cl}_{2}$ and ethyl acetate. Residual solution was removed under vacuum after dried over $\mathrm{MgSO}_{4}$. The crude product obtained was dissolved in dry $\mathrm{THF}$ and added into a degassed solution of $\mathrm{SnCl}_{2}(0.6 \mathrm{mmol})$ in THF $(10 \mathrm{~mL})$ and concentrated $\mathrm{HCl}$ aqueous solution $(12 \mathrm{~mol} / \mathrm{L}$, $1.1 \mathrm{~mL})$. The resulting suspension was stirred at room temperature for $4 \mathrm{~h}$, and saturated $\mathrm{NaHCO}_{3}$ solution was added dropwise to neutralize redundant $\mathrm{HCl}$. After extracted with $\mathrm{CH}_{2} \mathrm{Cl}_{2}$, dried over $\mathrm{MgSO}_{4}$ and concentrated under reduced pressure, the crude mixture was passed through a short silica gel column with the elution of mixed petroleum ether/dichloromethane $(V: V=4: 1)$, purified with acetone and recrystallized from hexane to afford [7]CPPPy 2,7 as greenyellow solid (30 mg, 20.5\%). m.p. not melt when heated to $300{ }^{\circ} \mathrm{C} ;{ }^{1} \mathrm{H}$ NMR $\left(\mathrm{CDCl}_{3}, 400 \mathrm{MHz}\right)$ $\delta$ : $8.16(\mathrm{~s}, 4 \mathrm{H}), 7.88(\mathrm{~s}, 4 \mathrm{H}), 7.66(\mathrm{~d}, J=8.8 \mathrm{~Hz}, 4 \mathrm{H})$, $7.45 \sim 7.52(\mathrm{~m}, 24 \mathrm{H}) ;{ }^{13} \mathrm{C} \mathrm{NMR}\left(\mathrm{CDCl}_{3}, 101 \mathrm{MHz}\right) \delta$ : $138.49,138.25,138.15,138.08,137.99,137.95,137.89$, $136.74,131.93,128.20,127.85,127.75,127.66,127.52$, 127.50, 127.46, 127.43; HR-MS (MALDI-TOF) calcd for $\mathrm{C}_{58} \mathrm{H}_{36}[\mathrm{~m} / \mathrm{z}]^{+}$732.2817, found 732.2870.

\subsection{Emission lifetime measurements of [7]CPPPy 2,7}

Time-resolved fluorescence decay was monitored using a HORIBA FluoroCube-JY system. [7]CPPPy 2,7 was dissolved into $\mathrm{CH}_{2} \mathrm{Cl}_{2}$ and degassed to obtain a dilute solution. Emission lifetime was measured at room temperature following excitation at $390 \mathrm{~nm}$ from a pulsed diode laser (1.2 ns pulse duration). Detected at $492 \mathrm{~nm}$, photons were recorded until the peak channel contained $\sim 10^{3}$ counts. The kinetics of fluorescence delay is well described by an exponential function with a single time constant.

Supporting Information Synthesis route for compound 5, HR-MS and NMR spectra for [7]CPPPy ${ }_{2,7}$ and details of computational studies. The Supporting Information is available free of charge via the Internet at http://siocjournal.cn/.

\section{References}

[1] (a) Iyoda, M.; Yamakawa, J.; Rahman, M. J. Angew. Chem. Int. Ed. 2011, 50, 10522 .

(b) Miki, K.; Ohe, K. Chem. Eur. J. 2020, 26, 2529.

[2] (a) Liu, S. H.; Hou, H.; Deng, Z. Y.; Wang, X. R.; Tang, C.; Ju, Y. Y.; Feng, L. B.; Tan, Y. Z. Sci. China Chem. 2020, 63, 1626.

(b) Pun, S. H.; Miao, Q. Chin. J. Org. Chem. 2020, 40, 3347 (in Chinese).

(潘世豪，缪谦，有机化学, 2020, 40, 3347.)

[3] (a) Rusin, O.; Lang, K.; Kral, V. Chem. Eur. J. 2002, 8, 655. (b) Sinn, S.; Biedermann, F. Isr. J. Chem. 2018, 58, 357.

[4] (a) Müller, S.; Müllen, K. Philos. T. R. Soc. A 2007, 365, 1453. (b) Dzyuba, E. V.; Baytekin, B.; Sattler, D.; Schalley, C. A. Eur. J. Org. Chem. 2012, 2012, 1171.

[5] (a) Hanack, M.; Dini, D.; Barthel, M.; Vagin, S. Chem. Rec. 2002, 2, 129.

(b) Raymond, J. E.; Bhaskar, A.; Goodson, T.; Makiuchi, N.; Ogawa, K.; Kobuke, Y. J. Am. Chem. Soc. 2008, 130, 17212.

(c) Carlmark, A.; Malmstrom, E.; Malkoch, M. Chem. Soc. Rev. 2013, 42, 5858 .

[6] (a) Xin, P. Y.; Tan, S.; Wang, Y. D.; Sun, Y. H.; Wang, Y.; Xu, Y. Q.; 
Chen, C. P. Chem. Commun. 2017, 53, 625.

(b) Zheng, S. P.; Huang, L. B.; Sun, Z. H.; Barboiu, M. Angew. Chem. Int. Ed. 2020, 60, 566.

[7] (a) Jasti, R.; Bhattacharjee, J.; Neaton, J. B.; Bertozzi, C. R. J. Am. Chem. Soc. 2008, 130, 17646.

(b) Takaba, H.; Omachi, H.; Yamamoto, Y.; Bouffard, J.; Itami, K. Angew. Chem. Int. Ed. 2009, 48, 6112.

(c) Yamago, S.; Watanabe, Y.; Iwamoto, T. Angew. Chem. Int. Ed. 2010, 49, 757.

[8] (a) Huang, Q.; Zhuang, G. L.; Jia, H. X.; Qian, M. M.; Cui, S. S.; Yang, S. F.; Du, P. W. Angew. Chem. Int. Ed. 2019, 58, 6244.

(b) Wang, J. Y.; Zhuang, G. L.; Huang, Q.; Xiao, Y. F.; Zhou, Y.; Liu, H. Q.; Du, P. W. Chem. Commun. 2019, 55, 9456.

(c) Wu, Y.; Zhuang, G.; Cui, S.; Zhou, Y.; Wang, J.; Huang, Q.; Du, P. Chem. Commun. 2019, 55, 14617.

[9] (a) Guo, L. F.; Yang, X. D.; Cong, H. Chin. J. Chem. 2018, 36, 1135.

(b) Xu, W.; Yang, X. D.; Fan, X. B.; Wang, X.; Tung, C. H.; Wu, L. Z.; Cong, H. Angew. Chem. Int. Ed. 2019, 58, 3943.

[10] Qiu, Z. L.; Tang, C.; Wang, X. R.; Ju, Y. Y.; Chu, K. S.; Deng, Z. Y.; Hou, H.; Liu, Y. M.; Tan, Y. Z. Angew. Chem. Int. Ed. 2020, 59, 20868.

[11] Tang, H.; Gu, Z.; Qiao, C.; Li, Z.; Wu, W.; Jiang, X. CCS Chem. 2020, 2,1851

[12] Chen, H.; Gui, S.; Zhang, Y.; Liu, Z.; Miao, Q. CCS Chem. 2020, 2 , 613.

[13] Shi, T.-H.; Wang, M.-X. CCS Chem. 2020, 2, 916.

[14] Fan, W.; Han, Y.; Dong, S.; Li, G.; Lu, X.; Wu, J. CCS Chem. 2020, 2,1445 .
[15] (a) Iwamoto, T.; Kayahara, E.; Yasuda, N.; Suzuki, T.; Yamago, S. Angew. Chem. Int. Ed. 2014, 53, 6430.

(b) Yagi, A.; Venkataramana, G.; Segawa, Y.; Itami, K. Chem. Commun. 2014, 50, 957.

[16] Xia, J. L.; Jasti, R. Angew. Chem. Int. Ed. 2012, 51, 2474.

[17] Golder, M. R.; Jasti, R. Acc. Chem. Res. 2015, 48, 557.

[18] Zhao, H. Y.; Ma, Y. C.; Cao, L.; Huang, S. Q.; Zhang, J. P.; Yan, X Y. J. Org. Chem. 2019, 84, 5230.

[19] (a) Coventry, D. N.; Batsanov, A. S.; Goeta, A. E.; Howard, J. A. K.; Marder, T. B.; Perutz, R. N. Chem. Commun. 2005, 2172. (b) Crawford, A. G.; Liu, Z. Q.; Mkhalid, I. A. I.; Thibault, M. H.; Schwarz, N.; Alcaraz, G.; Steffen, A.; Collings, J. C.; Batsanov, A. S.; Howard, J. A. K.; Marder, T. B. Chem. Eur. J. 2012, 18, 5022.

[20] Sasaki, S.; Suzuki, S.; Igawa, K.; Morokuma, K.; Konishi, G. J. Org. Chem. 2017, 82, 6865.

[21] Cui, S. S.; Zhuang, G. L.; Lu, D. P.; Huang, Q.; Jia, H. X.; Wang, Y.; Yang, S. F.; Du, P. W. Angew. Chem. Int. Ed. 2018, 57, 9330.

[22] Figueira-Duarte, T. M.; Müllen, K. Chem. Rev. 2011, 111, 7260.

[23] Yang, Y. J.; Xu, L.; Wang, H. Chin. J. Org. Chem. 2020, 40, 1658 (in Chinese). (杨玉杰, 徐莉, 王华, 有机化学, 2020, 40, 1658.)

[24] Sahoo, D.; Narayanaswami, V.; Kay, C. M.; Ryan, R. O. Biochemistry 2000, 39, 6594.

[25] Gaussian 09, Revision A.01; Frisch, M.; Trucks, G.; Schlegel, H.; Scuseria, G.; Robb, M.; Cheeseman, J.; Scalmani, G.; Barone, V.; Mennucci, B.; Petersson, G.; Inc; Gaussian, Inc., Wallingford CT, 2009.

[26] Feher, P. P.; Purgel, M.; Joo, F. Comput. Theor. Chem. 2014, 1045, 113.

$(\mathrm{Lu}, \mathrm{Y}$. 